\title{
Formation of Public Health Care on Basis of Healthy Lifestyle
}

\author{
Evgeniy Bryndin ${ }^{1}$, Irina Bryndina ${ }^{2}$ \\ ${ }^{1}$ Research Centre "NATURE INFORMATIC", Technological Platform Future Medicine, Novosibirsk, Russia \\ ${ }^{2}$ Pediatric Faculty, Novosibirsk State Medical University, Novosibirsk, Russia \\ Email address: \\ bryndin@ngs.ru (E. Bryndin), iriska26@ngs.ru (I. Bryndina)
}

\section{To cite this article:}

Evgeniy Bryndin, Irina Bryndina. Formation of Public Health Care on Basis of Healthy Lifestyle. International Journal of Psychological and Brain Sciences. Vol. 2, No. 3, 2017, pp. 63-68. doi: 10.11648/j.ijpbs.20170203.11

Received: April 11, 2017; Accepted: May 3, 2017; Published: June 29, 2017

\begin{abstract}
The World Health Organization considers that health of the person for $75 \%$ his conduct of life and a power supply system, for $10 \%$ - heredity determines, another $10 \%$ - environmental conditions, and only for $5 \%$ of service of health care. Health of the person most of all depends on a conduct of life. Natural and spiritual processes and a healthy lifestyle help the person and society to be healthy. The family and public culture of a healthy lifestyle and social infrastructure of a health-saving are fundamentals of public health care. Socially infrastructure of transition of the population to a healthy lifestyle matters for formation of healthy human resources of all age and all segments of the population. If the family and public culture of a healthy lifestyle be transferred from generation to generation, then really public health care will be created. In article health saving aspects which promote are considered to become to health care, really, public.
\end{abstract}

Keywords: Natural and Spiritual Aspects of Health, Family Culture of a Healthy Lifestyle, Infrastructure of Public Health Care, Spiritual Processes of Society, Global Healthy Wellbeing

\section{Introduction}

In medical community various approaches to a concept health were created: hygienic, adaptive, genetic, prenosological, safe, equilibrium, physiological, psychological, on health, viable, self-regulating, endoecological, resonant, spiritual, naturalistic and the combined approaches. We will consider spiritually naturalistic approach to a concept health. Approach is based on processes of the nature and a spiritual entity of the person.

\section{Natural and Spiritual Aspects of Health}

In the middle of the last century professor of Technical University of Munich of Winfried Otto Schumann has established that Earth and its ionosphere form the huge resonator where waves of ultralow frequencies which without effort can repeatedly bend around Earth extend. Within 60 years after the numerous researches and rechecks the frequency of Earth of $8 \mathrm{~Hz}$ has been determined. Since then in science this frequency is called the frequency of a resonance of Schuman. Formation of standing waves in such resonator has been called Schuman's resonance subsequently.

Doctor Robert Becker, measuring brain waves during the sessions of remote influence has established that these waves coincide with Schuman's waves. Besides, waves of the right and left cerebral hemispheres at such moments, are equal on frequency and are opposite on amplitude that leads to formation of standing waves. Standing waves of a brain are capable to enter interaction with Schuman's waves. Doctor Robert Becker is convinced that the uniform vibration frequency capable to influence live surrounding objects including on water is the cornerstone of the universe. He has measured waves of a brain of many spiritual healthy people. He has found out that all of them have identical frequencies $8 \mathrm{~Hz}$, isn't dependent on their religious and spiritual traditions, and are synchronized with Schuman's waves both on frequency, and on a phase. Healthy people have balanced mentality and a resonance of cages in a biofield at a vibration frequency of 8 hertz [1-5].

Health of the person is a psychophysiological state with balanced mentality and functioning of an organism at an electromagnetic frequency of cages of 8 hertz and with a 
wavelength of 8 meters in the resonance mode in environmentally friendly internal and the environment.

In the USA (NASA) and Germany (M. Planck's institute) long experiments as a result of which it has been established that Schuman's waves are necessary for synchronization of biological rhythms and normal existence of all live on Earth were made. Today the electromagnetic background of the planet as a result of activity of the person has undergone essential changes and is polluted to such an extent that the organism doesn't hear" Schuman's waves. For this reason of NASA uses generators of waves of Schuman for ensuring normal activity of personnel. Schuman's waves is a real vital factor.

In the 50th years of the 20th century it has been proved that intensity of a resonance of Schuman directly influences higher nervous activity of the person, and also his mental abilities. Thanks to a resonance of the waves of Schuman having a natural origin and standing waves of a brain, spiritual people for whom a cerebral hemisphere work in a synchronous rhythm have a healthy state. The science has confirmed it experimentally.

The medicine develops, and health of society worsens. It is more and more medicines; it is more and more surgical interventions; it is more and more hi-tech devices - and diseases advance medical medicine. We began to live longer, but quality of our life is worse, we feel worse. The medicine isn't guided by the spiritual principles and criteria of health therefore she doesn't fight for health, and is at war with diseases. In society more knowledge how to get rid of diseases, and less how to be healthy is accumulated.

Human life has the spiritual nature which cornerstone spiritual processes are. Spiritual processes of activity of the person and society are closely connected. They will help to get and keep health to mankind on a global scale [6]. Spiritual infrastructure of society influences in global and defining way health of everyone. To restore and keep health, understanding of spiritual processes of health is necessary. It is necessary to study spiritual that you don't see, you don't feel, you don't realize. There is a global interrelation between spiritual processes of the person and his physical health. Spiritual quality, as well as physical, gives in to a training. From a spiritual state to a healthy state will bemorerather. Interrelation between spiritual processes of the person and his physical health, and also a condition of all society, fundamental. Supports a healthy condition of the person spiritual mental energy which is generated by a spiritual thoughtway, an ethical image of the word, good wishes, a healthy image of activity in an ecological pure environment, spiritual bonds with society, love to a visible and invisible environment. Accumulating spiritual mental energy, the person increases also health creative working capacity.

The person with health creative working capacity can be protected by spiritual mental energy from infectious diseases, be exempted from cancer, diabetes and other diseases that is confirmed with practice on the basis of spiritual knowledge. Spiritual knowledge is valid healthy life: "My son! Listen to my words, and to my speeches bend your ear; yes they don't depart from your eyes; store them in your heart: because they life for this purpose who has found them, and health for his all body (Parable 4:20-22)." Researchers have experimentally confirmed positive preventive influence of spiritual doctrines and processes on improvement of the person and all wildlife. Spiritual processes of difficult essence of the person and society are connected with natural processes of improvement. At the end of the last century the scientific world has been excited by results of experiments of the Japanese scientist Masaru Emoto, visually proved that water under the influence of our thoughts, emotions, words changes the structure. Masaru Emoto's experiments convincingly prove that the spiritual word makes healthy impact in a resonance with Schuman's wave.

It is necessary to make active spiritual health the supporting processes:

1. In pedagogics: to bring up the social and spiritual citizen with health creative outlook.

2. In art: to lift the person on a creative line item of spiritual and physical health.

3. In medicine: to create health saving medicine.

4. In production: to realize programs of activization of the healthy spiritual collective processes allowing workers of the sphere of production to be adjusted on the optimum working condition of high-productive and high-quality work.

5. In education: to realize programs of spiritual health and a healthy lifestyle.

6. In society: to create public tradition of a healthy lifestyle.

7. In a family: to create family tradition of a healthy lifestyle.

\section{Family Culture of a Healthy Lifestyle}

The family culture of a healthy lifestyle is a health saving practice by the health supporting actions which are consciously fixed in useful habits. The family culture of a healthy lifestyle includes formation of health creative outlook, motivation to a healthy lifestyle and development of a healthy lifestyle by parents and children in house conditions. The motivation of a healthy lifestyle takes the central place in formation and preservations of health of each person. The motivation of a healthy lifestyle is understood as awareness of need of preservation of health by the person as bases for manifestation in various spheres of activity as bases of harmonious development. In the absence of motivation at the person any programs and actions for preservation of health will be poorly effective or aren't productive at all. The family culture of a healthy lifestyle will lead to revival of a cult of a healthy and full-fledged family as bases of society and the state. The proverb says: "The family is strong - the Power is strong". Along with motivation on a healthy lifestyle children have to acquire a certain complex of knowledge, skills of preservation and strengthening of the health. The healthy lifestyle is the most optimum system of behavior of the person in everyday life allowing him to 
realize as much as possible the spiritual and physical qualities for achievement of mental, physical and social wellbeing. It is the integral, logically interconnected, thought over and planned system of behavior of the person which he carries out not on coercion, and with pleasure and confidence that it supports a healthy state.

The healthy state is reached and supported in the environmentally friendly natural and spiritual social environment by the healthy lifestyle including preventive health the supporting spiritual and corporal clarifications, and also physical exercises of normalization, first, physiological rhythms gymnastics, secondly, of a power system charging, thirdly, of a tone of muscles of an organism physical culture. "The person moderately and in due time engaged in physical exercises doesn't need treatment" (Science about preservation of health (part 2), the scientist, the doctor Avicenna). It is also necessary to go in for physical culture for the purpose of maintenance up to standard of the biological body all life, differently fabrics and bodies which are used, atrophy a little and even die off.

Transfer of family culture of a healthy lifestyle from generation to generation from generation to generation will create family tradition of a healthy lifestyle.

\section{Technique of Transition to a Healthy Lifestyle}

Transition to a healthy lifestyle is carried out in four stages of formation of useful habits [7-10].

Stage 1. Formation of useful habits of maintenance of hygienic and endoecological purity of an organism. Habits are formed on performance of hygiene and endoecology. The pure environment of an organism and cages is one of necessary conditions of a wave resonance of cages. Purity guarantee of health.

Stage 2. Development of useful habits of achievement of spiritual, and power purity and healthy state. Spiritual and power purity are necessary conditions of a wave resonance of cages.

Stage 3. Acquisition of useful habits health of saving for preservation of a healthy state.

Stage 4. Accumulation of experience of preservation of a healthy state useful habits within a year. Accumulation of experience is carried out by useful habits health of saving in various house, social and natural seasonal conditions (in the spring, in the summer, in the fall and in the winter).

\section{Public Culture of a Healthy Lifestyle}

The healthy lifestyle is a key to the healthy nation. The first and most important condition for introduction of a healthy lifestyle, change of world outlook consciousness of the population is. Consciousness of people has to pay attention to health, a healthy lifestyle. A main goal of a healthy lifestyle - realization of spiritual, professional and physical development of the person. Potential of spiritual and physical development of the person, consist in unity of kind thoughts, words and affairs. And this good should be directed to all world around: on close and distant, on the family, the sort, the people, the fatherland, a civilization, on mankind and all biosphere. It is necessary therefore that the person got support from the outside. If he cares for the family, then will get support from a family if about a sort - from a sort if about the people - from the people, etc. And it is necessary to do it throughout all the adult life. It has to be the normal state of the person. Transition of the people to a healthy and just way of life will lead to decrease in social tension in society, to acceleration of process of transition to a steady course of development, to strengthening of economic and defensive power, to blossoming of science, culture, to decrease in expenses on health care, reduction of human and material losses owing to decrease in level of accidents of social and technical character. If the most part of people on Earth leads a healthy lifestyle, then the most part of other problems will be solved not only demographic, but also:

a. the environment ecology will significantly improve;

b. the power of all levels will govern for the benefit of healthy society;

c. on the planet Earth will be restored healthy climate;

d. the mankind will find harmony with the Nature;

e. the public culture of a healthy lifestyle will be created.

The public culture of a healthy lifestyle consists of set health saving the practician, which are formed on the base of moral and religious and national cultures and traditions which provide to the person a physical healthy state and mental, spiritual and social well-being in the real environment [4]. Health the preserving practice of public culture of a healthy lifestyle is family culture. She makes active the population on mass development of a healthy lifestyle.

Transfer of public culture of a healthy lifestyle from generation to generation will create public tradition of a healthy lifestyle [11].

For realization of set health saving the practician of public culture of a healthy lifestyle it is necessary to create social infrastructure of public health care.

\section{Social Infrastructure of Public Health Care}

Social infrastructure of public health care includes educational, professional, supporting health, service, propaganda and legislative substructures [12-16]. Social infrastructure is directed to increase in knowledge on health issues and his protection, to formation of skills of strengthening of health, creation of conditions for maintaining a healthy lifestyle, both certain people, and society in general. The kindergarten, school, higher education institutions, the centers of health, physical culture objects, health saving medicine teach skills of a healthy lifestyle. The propaganda structure performs function of information dissemination of knowledge for all categories of the 
population about a health and healthy lifestyle. The service structure carries out healthy food, the organization of active recreation, mass morning exercises, creation bicycle and racetracks, dance floors, green zones used for outdoor games, etc.

The supporting health structure includes nurseries improving the camp for formation of skills of a healthy lifestyle at younger generation, the centers of health for development of a healthy lifestyle, hygienic and endoecological complexes. The educational structure trains specialists in training of the population in transition to a healthy lifestyle:

1. Experts for the centers of health and sanatorium institutions for carrying out consultations, a practical training for transition to a healthy lifestyle.

2. Lecturers on formation health of creative outlook, to education and motivation of the population to a healthy lifestyle.

3. Pedagogical workers for universities and schools on formation health of creative outlook, to education to a healthy lifestyle of the younger generation.

4. Social workers for carrying out a practical training with the population on transition to a healthy lifestyle and formation of family and cultural public tradition of a healthy lifestyle.

5. Games-masters for training of the younger generation in control of vital systems for healthy functioning of an organism.

The professional structure realizes organizational measures of preservation of health of the working population. Health influences quality of a manpower, productivity of social activities and by that dynamics of economic development of society. During life 1/3 general times the professional person participates in work. Therefore it is important that under the influence of work there hasn't occurred deterioration in health. For this purpose it is necessary to reduce adverse production factors to a minimum. Health of a working resource is area of mutual interests of the state, society, business and person. Responsibility for health of the nation lies on each of the called subjects. The health saving environment has basic value for preservation of health of a labor resource. Have to be tasks of the rational organization of activity concerning the professional status of the person, first, ensuring high level of professional working capacity, and secondly - minimization of the adverse factors of professional activity influencing health of the person. It is legislatively necessary to provide the organization of physical activity:

a. available visit of the pool, gym, various sections, monthly holding actions for a healthy lifestyle indoors and outdoors;

b. creation of material and technical resources: stock and equipment for physical culture and active recreation;

c. creation of service for restoration of healthy functioning of an organism.

It is necessary to provide spiritual education.

Spiritual processes of society and global healthy wellbeing
Human life has the spiritual nature which cornerstone spiritual processes are. Spiritual processes of activity of the person and society need to be cultivated consciously in society [2]. They will help to gain health to mankind on a global scale. Institutions of education, improving institutions, art, spiritual faiths, mass media have to conduct information activization of spiritual processes.

Spiritual infrastructure of society influences in global and defining way health of everyone. Quickly it is necessary to restore, keep and improve health, spiritual and physical shape of the person and society understanding of spiritual processes of health.

There is a global interrelation between spiritual processes of the person and his physical health. We destroy ourselves by harmful passions from within. All of us at each other influence - one and all. The spiritual state, as well as physical, gives in to a training. From a spiritual state to a healthy state - much more quickly.

The interrelation between spiritual processes of the person and his physical health (and also a condition of all society) is more considerable, than it is considered to be now. Moreover she - fundamental. Improvement of the person happens a positive mental energy which is generated by a spiritual thoughtway, in an ethical way of the word, good wishes, a healthy image of activity in an ecological pure environment, spiritual bonds with society and God, love to surrounding visible and invisible.

Structure of spiritual processes of the person - a major factor of influence on health. Our culture (theater, cinema, television, radio, a platform, other media) strongly influence our physical and spiritual health - either harmonize us, or destroy. "Now the television, cinema so spiritually us destroys that children from it are sick.

The accented understanding of spiritual processes, is also important for the person, as well as mastering the speech and writing.

Condition of society catastrophic: every year functional diseases, congenital pathologies at children, drug addiction increase. The medicine develops, and health of society worsens. It is more and more fine medicines - you watch how many them; it is more and more clever surgical interventions; it is more and more clever devices - and diseases advance mankind. The medicine isn't guided by the principles and criteria of health of the Creator therefore she doesn't fight for health, and is at war with diseases. We began to live longer, but quality of our life is worse, we feel worse.

It is necessary to connect together global problems of health, mass media, pedagogics, art; to see essentially new way of development of human community, to find conscious balance of spiritual infrastructure of society. To recover health, and to children first of all, it is possible only this way. The mankind has no other way.

All of us intuitively feel that something occurs now not as has to be - and we don't understand that. We intensified spiritless processes in us. We, first of all, destroy ourselves from within. All recommendations of science, psychology, medicine don't help already. Global amount of information 
useful, necessary we hear. But nothing helps us any more!

Spiritual processes, generally for $95 \%$, lie out of the sphere of consciousness of the person. The person realizes only a final stage of work of the functional program - incentive which, just and has to induce him to do something. We don't feel as we approach a disease - we only feel a disease. We don't know what state at us: healthy or prediseases - it also lies out of consciousness. It is necessary to study spiritual that you don't see, you don't feel, you don't realize.

Spiritual processes of health are constructed on harmony of natural processes of difficult essence of the person. We know that there is a physical culture. If the person regularly does physical exercises on a muscle, then the muscle begins to grow, become stronger. And we know that there are people who do physical exercises especially for a training of muscles - some every day. Also we know that there are people who do physical exercises every day not specially, and in the course of work: lift weights, do extensions. And these so effective exercises and also lead to a physical fitness. But we don't notice that we do spiritual exercises every day where we worked and even staying at home! We don't notice what spiritual, as well as physical gives in to a training. And we do spiritual exercises every day: first, scrolling the habitual thoughts and feelings; secondly, unconsciously empathizing everything surrounding us. What you think of that and you train!

Unconsciously empathizing everything surrounding us, we do spiritual exercises. Oh, and bad it exercises. Generally it exercises of a disease and pathology. Around us there are a lot of sick interrelations. And we come home tired and devastated. And training every day, gradually we accumulate sick interrelations and also we bear them to all who surround us, especially to children as they are open and trust us and study at us. Also it turns out that we now the most part of time, without realizing it, intensify spiritual processes of a disease and pathology. We, communicating, quite often we give sores each other. Because human community sick. We everything at each other influence - all without any exception!

We don't empathize health! Daily joining in spiritual processes of health, everyone can significantly improve the health and others and keep it. Diseases leave, the person and people around begin to feel better physically and spiritually, it becomes easier to live. People at the spiritual level begin to understand how health depends on the environment, societies and begins to work selectively, according to the understanding: to take that it is necessary and to tell to children what is necessary for them. In the society of other way to recover health, at mankind isn't present!

It is necessary to do so that, empathizing, people received a healthy charge, intensified healthy processes, and they will begin to bear healthy interrelations. And we will begin to understand who us what bears, in the course of the activities and to welcome healthy processes. If it occurs, then the mankind would recover health in months! Relations in society would change, and personally it would become much easier for everyone to live and feel psychologically. It appears, it is possible to receive reorganization from the person having a high health creative fitness very quickly. The mankind used it the millennia. Spiritual processes of health quickly result in healthy wellbeing.

\section{Conclusion}

It is necessary to allocate mass media, pedagogics, medicine and art for globalization of health to show essentially new way of development of humanity and, on the present, to build infrastructure of public health care.

\section{References}

[1] E. G. Bryndin \& I. E. Bryndina. Natural-Science Aspects of Health. / Weber Medicine \& Clinical Case Reports. Vol. 1 (1). 2015. pp. 134-137.

[2] Bryndin E. G. Natural-science valuation method and achievements of health. "11th Euroasian conf. DONOZOLOGIYa 2015 - Problems of an assessment and prediction of a status of personal and population health in case of influence of risk factors. S-Pb.: Krismas. 2015. Pages 109-112.

[3] E. G. Bryndin. Spiritual and scientific bases of health. Germany: LAMBERT Academic Publishing. 2016. 120 pages.

[4] Bryndin E. G. Selfrecovery of a healthy status at the cellular level. the 12th Euroasianнауч. конф. DONOZOLOGIYa 2016 Biological factor and microbiological diagnostics when forming a healthy lifestyle. S-Pb.: Krismas. 2016. Pages 90-94.

[5] E. G. Bryndin, I. E. Bryndina. Natural-science aspects of health. S-PB.: / Scientific and practical J. "Donozologiya and Healthy Lifestyle" No. 2 (19) 2016. Pages 7-12.

[6] Bryndin E. G. Bryndina I. E Spiritual processes of society and global health. II Inter conf. "Information technologies in science, management, social sphere and medicine". TPU. 2015.

[7] Bryndin E. G., Bryndina I. E. Stages of transition to a healthy lifestyle. Second Ural Medical Forum "Healthy Family Healthy Russia". 2013.

[8] Bryndin E. G., Bryndina I. E. Formation of a healthy human resource. Collection of the International conference "HR trend of 2015". Publishing house TGU. 2016. Pages 163-166.

[9] Bryndin E. G. Bryndina I. E. Training in a healthy lifestyle in HIGHER EDUCATION INSTITUTION. Collection of the IX All-Russian scientific and practical conference "Physiological, Pedagogical and Environmental Problems of Health and Healthy Lifestyle". RGPPU. 2016. Page 43-48.

[10] E. G. Bryndin. Aspects of health and healthy lifestyle. VI REGIONAL SCIENTIFIC and PRACTICAL CONFERENCE "The Modern Aspects of Formation of a Healthy Lifestyle". NGMU "Sibmedizdat". 2017. Pages 39-43.

[11] Bryndin E. G. Culture of a healthy lifestyle. Third Arkaim conf. "Horizons of civilization". Chelyabinsk: ChSU. 2012. Pages 32-40.

[12] Bryndin E. G., Bryndina I. E. Management of social infrastructure of formation of a healthy lifestyle of the population. Intersymposium "Society and continuous wellbeing of the person". TPU. 2014. Page 102-106. 
[13] E. G. Bryndin. Formation of the healthy person, family and society. Germany: LAMBERT Academic Publishing. 2015. 93 pages.

[14] Bryndin E. G., Bryndina I. E. Formation of health saving medicine.//Electronic scientific and educational bulletin "Health and Education XXI Century". 2016. Volume 18, No. 11. M.: RUDN. Pages 28-31.
[15] E. G. Bryndin, I. E. Bryndina. Sanatorium Rehabilitation of the Population by the Healthy Lifestyle. International academic journal "Rehabilitation Sciences". 2017. Pages 3540 .

[16] Bryndin E. G., Bryndina I. E. Healthy Wellbeing of the Person and Society. Journal "The European Proceedings of Social \& Behavioural Sciences EpSBS". Volume XIX. 2017. Pages 130-139. 